\title{
Five Common HR Challenges Every Optometry Practice Faces
}

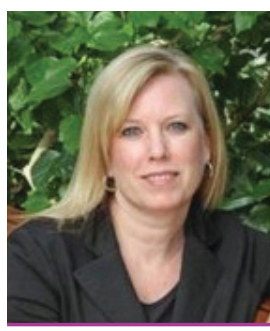

\section{Trudi Charest, RO}

Trudi Charest is the Co-Founder of Marketing4ECPs, a digital marketing agency focused in eye care. Marketing4ECPs assists Optometrists with website design, SEO, social media, digital marketing, Google Ads, email marketing and so much more. Trudi can be reached at trudi@4ecps.com or www.marketing4ecps.com.

$\mathrm{N}$ o matter the size of your optometry practice, you have likely experienced human resource issues. It's a fact that we cannot run practices without employees so understanding and preparing for the common challenges is a smart business strategy. Human resources can cover a broad spectrum of topics so let's tackle the top five.

\section{\#1 HIRING GOOD STAFF}

It continues to be the top challenge I hear every time I speak with a practice owner. Finding good staff is hard! We have all hired someone we thought was going to be amazing and then they started calling in sick or bringing negativity into the office. Recruiting well is an art and needs dedicated attention.

Solution: Be ready to recruit. Have a job posting created you can update as needed. Have a list of all the places you want to post your job from online jobsites to association job boards and college job fairs. But don't stop there ... post it on social media. Have your staff share it on their social. Spread as wide a net as possible so you get a decent size pool of candidates. Now spend the time reviewing each resume and set up interviews. Get your team involved in the hiring so you truly uncover whether the candidate is a fit for the culture and practice.

\section{\# 2 TRAINING \& DEVELOPMENT}

Unless you have worked in a structured, corporate environment with a full training department, most businesses don't have a training and development plan for employees. Training not only is a key to a successful and thriving practice, it is a strong retention strategy. Employees who feel like they are growing in their roles stay at businesses longer.

Solution: Build a training plan. Take advantage of training from sales reps, online portals from supplier companies and lunch and learn offerings. Look at events you and your staff can attend together, like association conferences, large CE events like Vision Expo or, if you belong to a buying group, check out what training resources and events they offer. An easy way to get started on training in your office is to do a quick training topic at every staff meeting. For example: This staff meeting we are going to spend 20 minutes discussing Glaucoma; what it is, how we diagnose it and the treatment options available. You are the expert passing on your knowledge to your team in small bite size sessions during your already scheduled meetings.

\section{\# 3 GROWTH OPPORTUNITIES}

Optometry practices often don't have a multitude of growth opportunities for employees. We might have a manager role, maybe even a dispensary manager or lab manager but we generally only have a few roles that staff can grow into. Employees, especially Millennial employees, need to feel they have career paths that include growth and actual career advancements. 
Solution: Create opportunities for staff to move into roles based on their skills. For example: a receptionist might want to become an optician, or an optician might want to also be the social media manager for the practice. Get creative ... what tasks and responsibilities exist in the office that if someone were to learn them and take them on, could be created as a new role and title?

\#4 COMPENSATION

Practice owners struggle with how best to handle compensation. Not just from a structure standpoint, like, when do I give a raise, but how much of a raise. You're often competing with chains with larger payroll budgets and full time HR managers who are actively recruiting and targeting your employees. As a small business owner, it's not just the wage that we're focused on, it's the extras like benefits, training, education, vacation and staff parties.

Solution: Salary is important but it's not everything. In fact, when we talk to employees they cite culture, environment, teamwork, people and work-life balance as the major factors for staying at a job. Ensuring you are doing more in those areas will gain you some leeway. Setting expectations of salary increases when you hire is a good way to keep it to an annual request. Another great way to drive revenue and employee satisfaction with wages is to offer bonuses based on performance - if revenue grows their salary grows.

\section{\# 5 TERMINATION}

Easily the most disliked human resource task a practice owner will have to complete in their business. There are many reasons termination may be required; the hard part is doing it. We keep bad employees for three reasons: one - we are too nice and don't want to hurt their feelings; two - we don't have the time to find a new employee and we're too busy to be down an employee; and three - we don't want to do the actual termination.

Solution: Don't keep bad employees! Just do it. It will force you to get on it and find a new employee faster. Your staff will understand and help you through it. In fact, there's a good chance they also want the bad employee gone. Prepare to terminate and do it fast but with empathy. If you're at all worried, need legal advice, or want someone else to do it, hire an HR expert.

Last note: HR challenges are normal. There are resources from online HR websites that can answer basic questions for employment lawyers when required. Your employees are your most important asset. Investing time into learning how to make HR work better in your business will pay you back in employee satisfaction and retention. $\bullet$

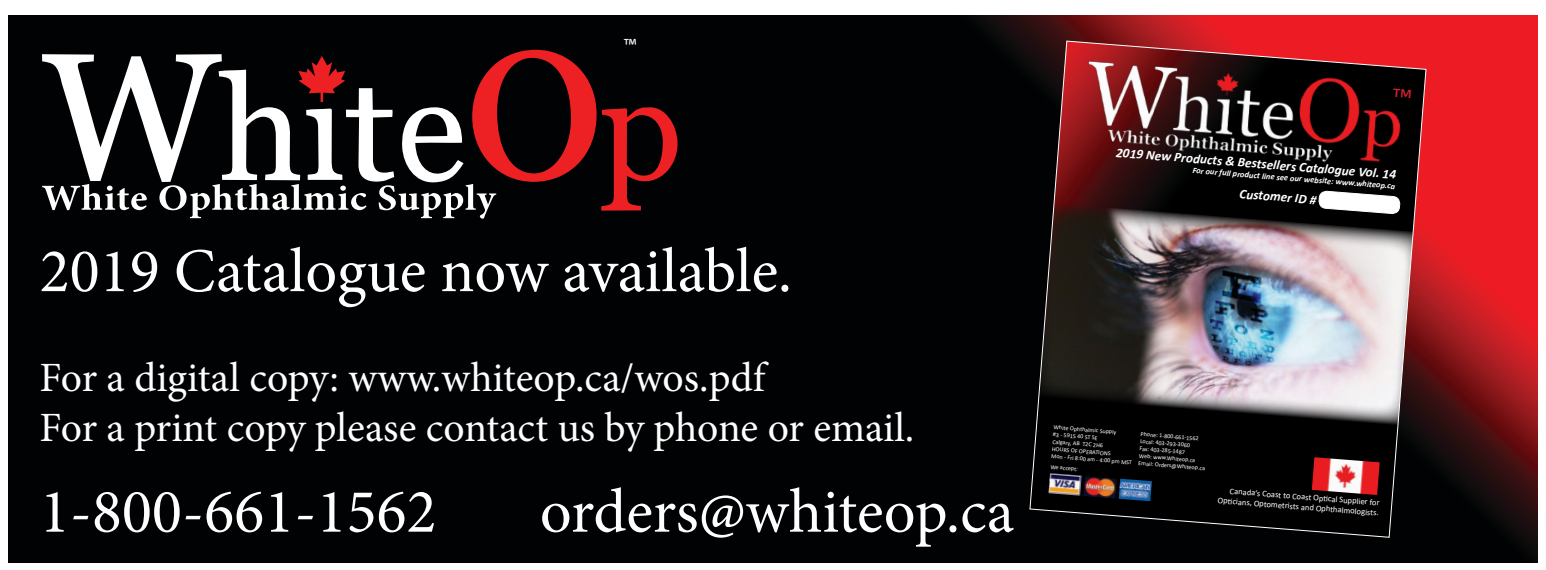

